\title{
Influence of ambient temperature on diurnal activity of Arabian oryx: Implications for reintroduction site selection
}

\author{
Philip J. Seddon and Khairy Ismail
}

\begin{abstract}
The distribution of the Arabian oryx Oryx leucoryx had declined markedly by the time European explorers documented distributions, and the species became extinct in the wild by the mid 1970s. Consequently, historical distribution records may be unreliable indicators of current habitat suitability for reintroductions. In this study diurnal behaviour of Arabian oryx was recorded within a central Saudi Arabian reintroduction site. Oryx were less active on warmer days due to an increase in shading (resting in shade) at the expense of feeding time; there was an inverse relationship between temperature and feeding. During hot conditions (maximum ambient temperature $>40^{\circ} \mathrm{C}$ ) some
\end{abstract}

individuals spent $<2$ hours feeding during the day, compared with an average of 4.8 hours during cooler weather. This suggests the importance of shade trees to permit year-round occupancy in reintroduction sites. Selection of sites according to documented historical distribution may focus on tree-less areas, probably formerly part of the winter range. Absence of shade could result in migration out of the reserve, into areas where oryx risk being shot.

Keywords Arabia, Arabian oryx, diurnal activity, Oryx leucoryx, reintroduction.

\section{Introduction}

The IUCN Guidelines for Reintroductions (IUCN, 1998) advise that reintroduction sites should be chosen "...within the historic range of the species...", further suggesting that care should be taken to select or prepare sites "...where the habitat and landscape requirements of the species are satisfied and likely to be sustained...".

For species such as the Arabian oryx Oryx leucoryx that became extinct in the wild, two challenges to reintroduction planning arise. Firstly, few accurate historical records are available with which to assess the former distribution of the species in the Arabian Peninsula. Secondly, prior to the first reintroduction of oryx in Oman in 1982, there was no quantitative ecological information with which to assess release site suitability. In Oman, the last stronghold of the species in the wild, final extirpation of Arabian oryx occurred some time in the early 1970s (Henderson, 1974) leaving only captive populations (Grimwood, 1988). The Omani oryx reintroduction project focussed on the stony plains of the Jiddat-al-Harasis, the site where the last oryx

Philip J. Seddon (Corresponding author) Department of Zoology, University of Otago, P.O. Box 56, Dunedin, New Zealand E-mail: philip.seddon@stonebow.otago.ac.nz

Khairy Ismail National Wildlife Research Center; National Commission for Wildlife Conservation and Development, P.O. Box 1086, Taif, Kingdom of Saudi Arabia

Received 14 June 2001. Revision requested 13 September 2001. Accepted 20 September 2001 were killed (Henderson, 1974) and which was known to have held a substantial oryx population at least up to the first half of the 1960s (Stanley Price, 1989). However, the suitability for oryx of other parts of the Arabian Peninsula is less certain because even by the 1900s the species' distribution had already been markedly reduced by over-hunting and other human related activities (Fig. 1) (Tsagarakis in press).

In the fierce summer temperatures of the Arabian Peninsula the presence of adequate shade within candidate reintroduction sites may be necessary for yearround residency by oryx (Child \& Grainger, 1990). In this paper we examine the diurnal activity of individual adult Arabian oryx free-ranging in central Saudi Arabia. We quantify behavioural responses, specifically resting and feeding behaviour, to ambient temperature to emphasize the importance of adequate shade within future reintroduction sites.

\section{Methods}

\section{Study site}

Observations were made on free-ranging adult Arabian oryx within the $2244 \mathrm{~km}^{2}$ Mahazat as-Sayd protected area in central Saudi Arabia. Mahazat as-Sayd is Saudi Arabia's only completely fenced wildlife protected area and is a reintroduction site for Houbara Bustards Chlamydotis undulata macqueenii (Seddon et al., 1995). A total of 76 captive-bred Arabian oryx were released into Mahazat as-Sayd between 1990 and 1994 (Ostrowski et al., 


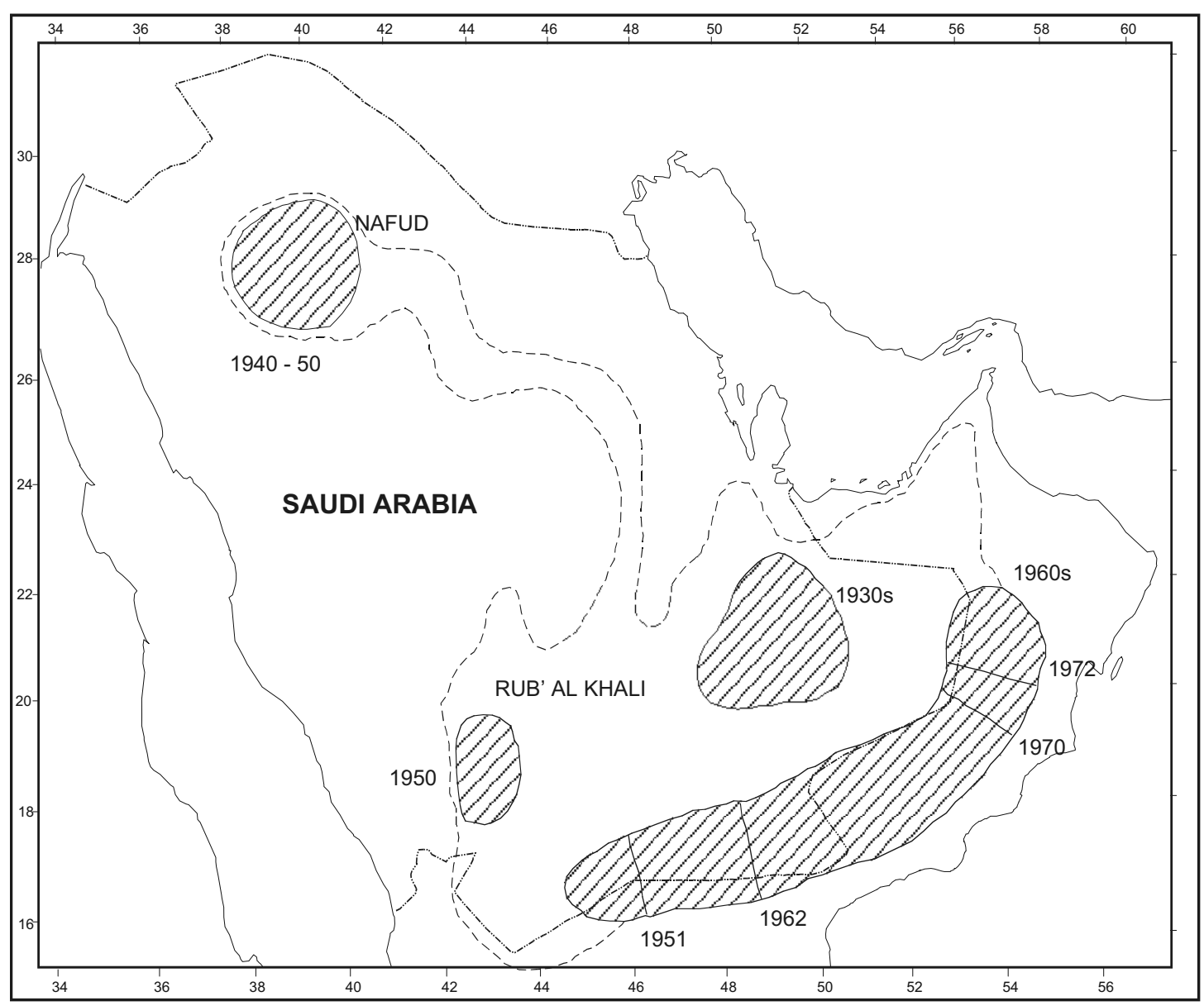

Fig. 1 Historical distribution of the Arabian oryx. Believed once to have ranged over much of the Arabian Peninsula, the Arabian oryx was restricted to two populations (cross-hatched regions), one north and one south, by the early 1900s. Dates next to cross-hatched regions are approximate dates of extirpation of oryx populations. The dotted line delimits the Arabian sand seas. (After Stanley Price, 1989).

1998). Recent estimates put the free-ranging population at over 300 animals (National Wildlife Research Centre, Saudi Arabia, unpublished data, 2000).

The protected area consists of a gently undulating sand and gravel plain at about $900 \mathrm{~m}$ altitude with a few low basalt hills rising to $1100 \mathrm{~m}$. There is rapidly recovering, extensive though still patchy vegetative cover (Fisher et al., 1998) of mostly dwarf shrubland with emergent small trees of Acacia tortilis and other Acacia spp., and of Maerua crassifolia, the latter being the only tree in the protected area of sufficient size to be used for shade by oryx. Robust perennial grasses, including Panicum turgidum, Lasiurus scindicus and Octhochloa compressa, which are important oryx forage species, are abundant on deeper sand and on low lying ground, while Stipagrostis spp. are more abundant in rocky areas. Many perennial shrubs and forbs grow among the perennial grasses. Haloxylon salicornicum dominates on alkaline soils.

\section{Observations}

We conducted focal animal samples of five minutes duration at ten-minute intervals throughout the day from 06.00 to 18.00 (corresponding to within approximately one hour of sunrise and sunset, respectively, throughout the year). We recorded the time spent in each of five broad behavioural states: feeding (actively grazing or browsing, chewing or head down searching), walking, standing at rest, bedded in shade, and other (including social interactions such as shrub horning, herding, chasing, courtship, mating and fighting). Observations for each day for each animal were compiled as percentages of time in each behaviour for 12 one-hour periods; i.e. 06.00-07.00, 07.00-08.00, etc. Focal animal observations were conducted on a total of 15 female and six male Arabian oryx. Ten of the 15 females and two of the six males were wild-born within the reserve; the others were founder animals released in 
Table 1 Summary of diurnal activity observations on Arabian oryx in central Saudi Arabia. Figures are number of days (number of individuals observed).

\begin{tabular}{lccl}
\hline Sex & $\begin{array}{c}\text { 'Warm' day } \\
\text { obervations }\end{array}$ & $\begin{array}{l}\text { 'Cool' day } \\
\text { observations }\end{array}$ & $\begin{array}{l}\text { Total days of } \\
\text { observations }\end{array}$ \\
\hline Males & $6(5)$ & $8(3)$ & $14(6)$ \\
Females & $8(7)$ & $12(8)$ & $20(15)$ \\
Totals & $14(12)$ & $20(11)$ & $34(21)$ \\
\hline
\end{tabular}

1990 or 1991. Observations were made on individual oryx during a total of 34 days between August 1992 and July 1993 (Table 1).

Ambient temperatures were measured continuously at an automatic meteorological recording station situated within the protected area, allowing the compilation of daily and annual average temperature curves for the study period. For each day of observation the following information was obtained: maximum, mean and minimum ambient temperatures ( $T$, degrees Celsius), mean $\%$ relative humidity, mean wind speed, rainfall, and an estimate of cloud cover given as solar radiation in $\mathrm{W} \mathrm{m}^{-2}$. Any definition of season in central Arabia is confounded by meteorological variability. Rather than attempt a seasonal division of the data, we classified observation days arbitrarily on the basis of the range and frequency of recorded ambient temperature as either 'warm' $\left(T_{\max }>35^{\circ} \mathrm{C}\right)$ or 'cool' $\left(T_{\max }<30^{\circ} \mathrm{C}\right)$. Observations made during days when $30^{\circ} \mathrm{C}<T_{\max }<35^{\circ} \mathrm{C}$ were excluded from the analysis.

\section{Data analysis}

Comparisons of the amount of time spent in different behaviours were made between males and females on warm and cool days using Mann-Whitney $U$-tests using actual percentages. When an individual was sampled on more than one warm or cool day, a mean percent- age was calculated each for warm day and for cool day comparisons between sexes. The relative effect of climatic variables on behaviour was examined through correlation of activity, using proportions of 1) time spent shading and 2) time spent feeding, transformed to their arcsine (arcsine sq. rt. $p$ ), against ambient temperature $\left(T_{\max }, T_{\min }, T_{\text {mean }}\right)$, rainfall, wind speed, solar radiation, and $\%$ relative humidity, for each day of observations. Spearman rank correlation coefficients $\left(r_{\mathrm{s}}\right)$ were calculated for each correlation, to indicate the relative importance of each climatic variable. When an individual had been observed on more than one day, one sample point was drawn at random for analyses.

\section{Results}

Ambient temperatures in Mahazat as-Sayd have a marked annual variation, with maximums in excess of $35^{\circ} \mathrm{C}$ for five months of the year (Fig. 2). There was no significant difference between males and females in the amount of time spent feeding, during warm $(U=17$, $n=12, P=0.94)$ or cool days $(U=6, n=11, P=0.22)$ (Table 2). The sexes were, therefore, combined for a comparison of behaviour between warm and cool days.

There was a significant difference between warm and cool days in the amount of time spent feeding $(U=8$, $n=23, P<0.001$ ), and in total activity (feeding, walking and other active behaviour; $U=10, n=23, P=0.001$ ). Oryx were less active on warm compared with cool days, principally through a reduction in the amount of feeding (Table 2). On cool days the mean time spent feeding was 4.8 hours whereas on warm days mean feeding time was reduced to 2.7 hours. Some individuals spent less than 2 hours feeding on the warmest days when maximum ambient temperatures were over $40^{\circ} \mathrm{C}$. There was a marked diurnal pattern in time spent feeding, with peaks in the morning and late afternoon during periods of lower ambient temperature; this pattern was more marked during warm days (Fig. 3).

Table 2 Mean time spent feeding and activity of male and female Arabian oryx during 'warm' and 'cool' days in central Saudi Arabia. Mean maximum ambient temperatures were calculated for each day of observations.

\begin{tabular}{|c|c|c|c|c|c|c|}
\hline Warm & $n$ & $T_{\max }\left({ }^{\circ} \mathrm{C}\right)$ & $\%$ time feeding (range) & hours per day feeding & $\%$ time active (range) & hours per day active \\
\hline Males & 5 & 38.75 & $21.98(19-34)$ & 2.6 & $49.45(36-65)$ & 5.9 \\
\hline Females & 7 & 38.13 & $22.29(12-36)$ & 2.7 & $37.95(35-52)$ & 4.6 \\
\hline Both sexes & 12 & 38.40 & $22.16(12-36)$ & 2.7 & $42.74(35-65)$ & 5.1 \\
\hline Cool & $n$ & $T_{\max }\left({ }^{\circ} \mathrm{C}\right)$ & \% time feeding (range) & hours per day feeding & \% time active (range) & hours per day active \\
\hline Males & 3 & 26.16 & $35.46(33-39)$ & 4.3 & $64.79(63-78)$ & 7.8 \\
\hline Females & 8 & 26.25 & $41.72(27-49)$ & 5.0 & $71.42(43-84)$ & 8.6 \\
\hline Both sexes & 11 & 26.22 & $40.01(27-49)$ & 4.8 & $66.6(43-84)$ & 8.0 \\
\hline
\end{tabular}




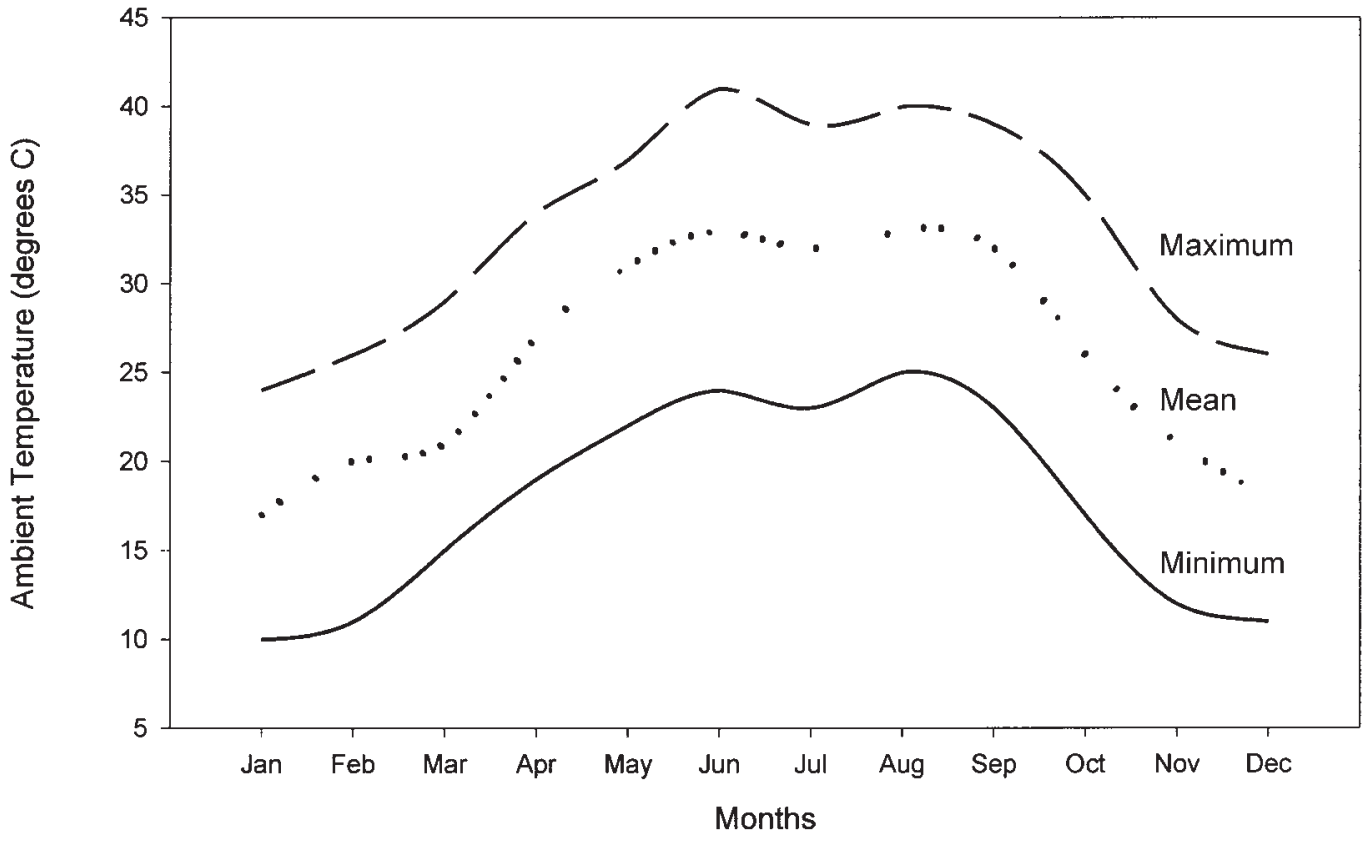

Fig. 2 Ambient temperatures measured throughout 1993 in the Mahazat as-Sayd Protected Area Arabian Oryx reintroduction site, central Saudi Arabia. Curves indicate mean maximum (dashed line), mean (dotted line) and mean minimum (solid line) monthly ambient temperatures.

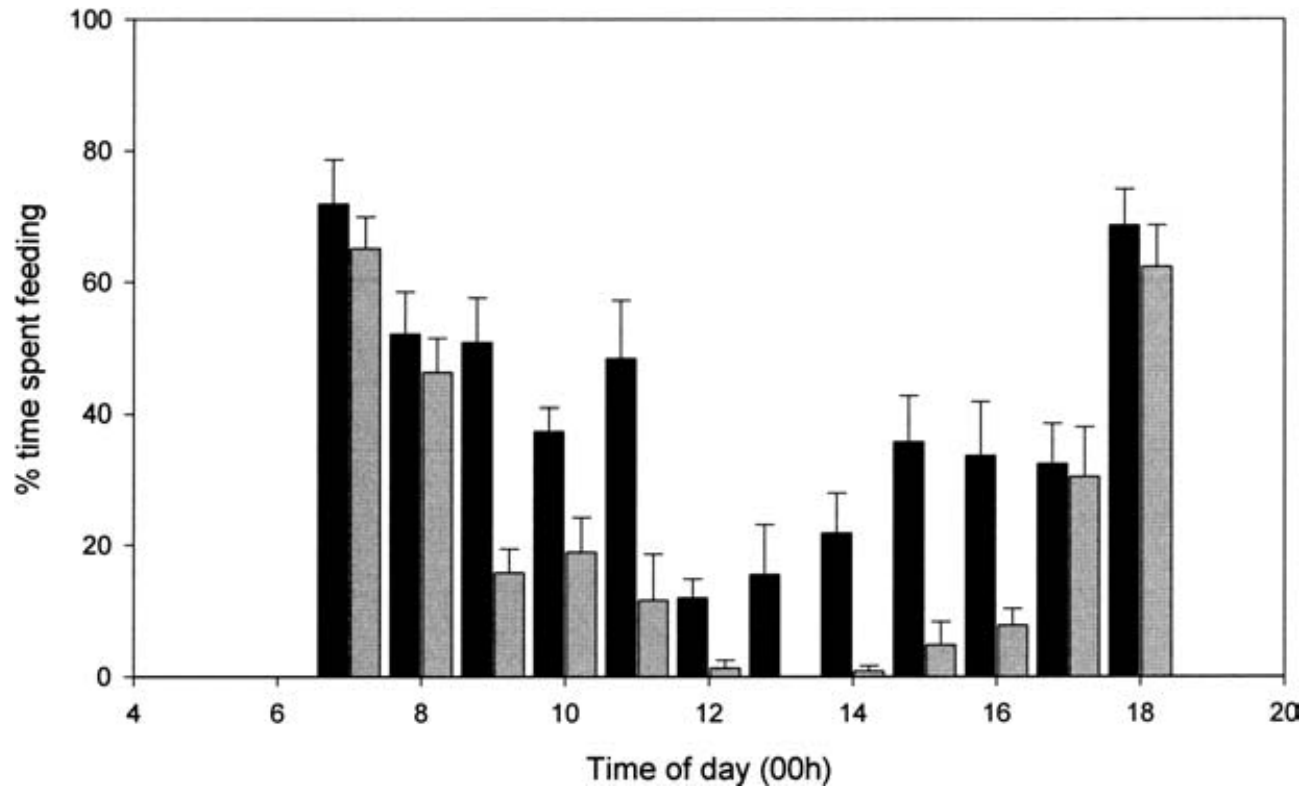

Fig. 3 Percentage of time spent feeding by Arabian oryx in central Saudi Arabia. Means +1 SE are shown for males and females combined on 'cool' days (dark bars; $n=11$ individual oryx) and 'warm' days (pale bars; $n=12$ individual oryx). Where there was more than one sample from an individual a single mean percentage was calculated within day type.

Correlation of shading against each of the climatic variables indicated the relative importance of both ambient temperature and solar radiation (Table 3). Time spent shading by oryx was strongly positively correlated with $T_{\max }, T_{\min }, T_{\text {mean }}$ and solar radiation; the hotter the weather, the more time spent in the shade. Increases in time spent resting were at the expense of feeding time. There was an inverse relationship between ambient temperature and time spent feeding (Table 3). Rainfall had the least direct effect on oryx behaviour. 
Table 3 Spearman rank correlation coefficients $\left(r_{\mathrm{s}}\right)$ between arcsine transformed proportions of time spent by oryx shading and feeding, and each of seven climatic variables. $N=20$ individual male and female oryx; where an individual was observed on more than one day, one sample point was drawn at random for analysis. Note: data from one female were excluded from the analysis because not all climatic data were available for the day on which she was observed.

\begin{tabular}{lcc}
\hline & \multicolumn{2}{c}{ Oryx Behaviour } \\
\cline { 2 - 3 } Climatic variable & Time in shade & Time feeding \\
\hline$T_{\max }$ & 0.741 & -0.644 \\
$T_{\operatorname{mean}}$ & 0.745 & -0.653 \\
$T_{\min }$ & 0.703 & -0.754 \\
Solar radiation & 0.746 & -0.455 \\
Rainfall & -0.216 & 0.114 \\
Windspeed & 0.497 & -0.363 \\
\% relative humidity & -0.442 & 0.273 \\
\hline
\end{tabular}

\section{Discussion}

Arabian oryx that have been re-established in the Arabian Peninsula experience high maximum ambient temperatures over a period of several months each year. Their response to such temperatures is to reduce activity and seek shade under mature trees of Maerua crassifolia, Acacia spp. or Prosopis cineraria, depending on the region, during the hottest times of the day (Stanley Price, 1989; this study). In general, the higher the ambient temperature the more of the day is spent in shade. The presence of adequate shade may therefore be a critical factor determining summer habitat suitability. Without the presence of shade trees oryx would be exposed to direct insolation and may experience difficulty maintaining a body temperature within the normal limits. With adequate shading sites during hot weather, oryx in Mahazat as-Sayd reduce their total diurnal feeding time by up to $60 \%$. A similar relationship between ambient temperature and shading behaviour was found for Arabian oryx in Oman (Stanley Price, 1989), although Stanley Price suggested that this relationship may be positively linear only above a threshold of $27^{\circ} \mathrm{C}$. Arabian oryx probably compensate for reduced feeding opportunities during warm days through nocturnal foraging (Stanley-Price, 1989; C. Magin unpublished data).

By early in the 20th century remnant Arabian oryx populations in the Arabian Peninsula appeared to be restricted to the sand seas of the Great Nafud in the north and areas of the Rub' al-Khali (Empty Quarter) in the south-east (reviews in Harrison and Bates, 1991; Ostrowski et al., 1998). However, these records are from the writings of European travellers to the region (Carruthers, 1935 and references therein), who often restricted their travels to the cooler winter months. What we may have therefore is an indication of the winter distribution of Arabian oryx, rather than a precise demarcation of their annual range. Areas such as the Nafud and the Empty Quarter are virtually devoid of trees and it is unlikely that Arabian oryx remained deep in the sands during the summer months. Oral tradition and observations of the movements of oryx within the 'Uruq Bani Ma'arid protected area, Saudi Arabia's unfenced second oryx reintroduction site, suggest that oryx move deep into the sands to exploit ephemeral vegetation following winter rainfall, but retreat to the treed fringes during summer (Wacher, 1998).

Given that the extent of lands that can feasibly be set aside from human development in the Arabian Peninsula is limited, it becomes important to select oryx reintroduction sites that can fulfil the annual habitat requirements of the species. For example, if oryx were to be reintroduced into a section of the Nafud desert, where the species was plentiful during the first part of the 20th century, a summer migration of released animals may occur, out of the treeless lands and into the surrounding relatively better vegetated agricultural lands. Hunting of Arabian oryx remains a major problem facing reintroduced populations, both in Oman (Gorman, 1999) and Saudi Arabia (E. Bedin, pers. comm.). In Saudi Arabia movement by oryx out of unfenced protected areas and into populated lands may result in animals being shot.

Selection and development of new oryx reintroduction sites is a priority of Saudi Arabia's National Commission for Wildlife Conservation and Development. The creation of a large metapopulation of Arabian oryx in the Peninsula through the creation and management of a network of reintroduction sites is seen as necessary to avoid a second wild extinction caused by catastrophic events (Ostrowski et al., 1998). This ultimate goal became even more urgent when the re-established Omani oryx population collapsed because of poaching during 1996-99 (Spalton et al., 1999).

The IUCN Reintroduction Guidelines (IUCN, 1998) acknowledge that habitats within the former range may have changed since species extirpation. Wood cutting for firewood and charcoal, and the loss of tree cover caused by overgrazing are widespread within the Arabian Peninsula (Fisher et al., 1998). A natural or man-made lack of mature shade trees, or lack of sufficient suitable shade trees to avoid intraspecific competition, will limit the number of suitable sites for future reintroductions, and in many areas could necessitate large-scale habitat restoration projects before oryx can be released. Recent climate models predict that temperatures in the Middle East will increase by $1-2^{\circ} \mathrm{C}$ by $2030-50$, and that impacts of climate change may be greater in semi-arid than in arid lands, especially in composition and distribution of 
vegetation types (IPCC, 2000). Regional climatic change could conceivably affect habitat suitability for Arabian oryx over the next 100 years. Human activity, however, is likely to continue to be the major factor acting to limit the potential of areas to support future reintroductions of Arabian oryx.

\section{Acknowledgements}

Arabian oryx restoration in Saudi Arabia proceeds with the support of HRH Prince Saud al-Faisal, and the efforts of Professor A. H. Abuzinada and his staff at the National Commission for Wildlife Conservation and Development (NCWCD). The Mahazat as-Sayd oryx restoration project is managed by the National Wildlife Research Center (NWRC) under the auspices of NCWCD, and is a success today through the endeavours and enthusiasm of the NWRC team. This paper was improved by the comments of Andrew Spalton, Yolanda van Heezik, David Mallon, Martin Fisher and an anonymous referee.

\section{References}

Carruthers, D. (1935) Arabian Adventure. H.F. \& G. Witherby, London.

Child, G. \& Grainger, J. (1990) A System Plan for Protected Areas for Wildife Conservation and Sustainable Rural Development in Saudi Arabia. NCWCD, Riyadh and IUCN, Gland.

Fisher, M., Ghazanfar, S.A., Chaudhary, S.A., Seddon, P.J., Robertson, E.F., Omar, S., Abbas, J.A. \& Boer, B. (1998) Diversity and Conservation. In Vegetation of Arabia (eds S.A. Ghazanfar \& M. Fisher). Kluwer Academic, The Netherlands.

Gorman, M. (1999) Oryx go back to the brink. Nature, 398, 190.

Grimwood, I.R. (1988) "Operation Oryx" the start of it all. In Conservation and Biology of Desert Antelopes (eds A. Dixon \& D. Jones), pp. 1-13. Christopher Helm, London.

Harrison, D.L. \& Bates, P.J.J. (1991) Mammals of Arabia. Harrison zoological museum. Sevenoaks, Kent, UK.

Henderson, D.S. (1974) Were they the last Arabian oryx? Oryx, $12,347-350$

IPCC (2000) The Regional Impacts of Climate Change. Intergovernmental Panel on Climate Change. UNEP and WMO.
IUCN (1998) Guidelines for Reintroductions. IUCN/SSC Reintroduction Specialist Group. IUCN, Gland, Switzerland and Cambridge, UK.

Ostrowski, S., Bedin, E., Lenain, D.M. \& Abuzinada, A.H. (1998) Ten years of Arabian oryx conservation breeding in Saudi Arabia - achievements and regional perspectives. Oryx, 32, 209-222.

Stanley Price, M.R. (1989) Animal Reintroductions: the Arabian Oryx in Oman. Cambridge University Press, Cambridge.

Seddon, P.J., Saint Jalme, M., van Heezik, Y., Paillat, P., Gaucher, P. \& Combreau, O. (1995) Restoration of houbara bustard populations in Saudi Arabia: developments and future directions. Oryx, 29, 136-142.

Spalton, J.A., Lawrence, M.W. \& Brend, S.A. (1999) Arabian oryx reintroduction in Oman: success and setbacks. Oryx, 33, 168-175.

Tsagarakis, C. in press. The distribution of the Arabian oryx Oryx leucoryx Pallas, 1777, from early days to nowadays. Proceedings of the First Abu Dhabi International Arabian Oryx Conference.

Wacher, T. (1998) Great white hope. BBC Wildlife, July 1998, 62-69.

\section{Biographical sketches}

Philip Seddon is currently directing the postgraduate wildlife management programme at the University of Otago in Dunedin, New Zealand, and is developing research interests in New Zealand species and habitat restoration projects. Between 1993 and 2000 he was research co-ordinator at the National Wildlife Research Center in Saudi Arabia, where his main research focus related to the reintroduction of houbara bustards, and the management of wildlife protected areas. He is a member of the IUCN's World Commission on Protected Areas and the Species Survival Commission, and current chair of the Bird Section of the SSC's Reintroduction Specialist Group.

Khairy Ismail is a field biologist based at the National Wildlife Research Center in Taif, Saudi Arabia. He has worked within the Mahazat as-Sayd protected area since its creation in 1989, and has been involved in all phases of the reintroduction of Arabian oryx. Although his work was initially focussed on an investigation of the status of the re-established Arabian oryx population, since 1995 he has directed the monitoring of reintroduced sand gazelle by ranger staff within the reserve. 